\title{
The relationship between selected socioeconomic factors and thinness among Polish school-aged children and adolescents
}

\author{
Beata Gurzkowska $^{1}$ - Zbigniew Kulaga ${ }^{1} \cdot$ Aneta Grajda $^{1} \cdot$ Magdalena Góźdź $^{1}$ • \\ Malgorzata Wojtyło ${ }^{1} \cdot$ Mieczyslaw Litwin $^{2}$
}

Received: 28 June 2016 / Revised: 6 April 2017 / Accepted: 17 April 2017 / Published online: 28 April 2017

(C) The Author(s) 2017. This article is an open access publication

\begin{abstract}
The analysis was performed on a database including 17,427 records of subjects aged 7-18 years, randomly sampled from a population of Polish students. Thinness was determined using international cut-off points, defined to pass through body mass index of $18.5 \mathrm{~kg} / \mathrm{m}^{2}$ at the age of 18 . The weighted prevalence of thinness and odds ratios with $95 \%$ confidence interval were estimated for gender, birth weight, level of schooling and school location, gross domestic product (GDP) per inhabitant, family income and maternal education. Body height was analysed according to body mass and birth weight categories. The prevalence of thinness was higher among children with low birth weight and among girls. The prevalence of thinness decreased with increasing GDP per inhabitant. In analysis by level of schooling: primary-
\end{abstract}

Communicated by Communicated by Mario Bianchetti

Mieczysław Litwin

m.litwin@ipczd.pl

Beata Gurzkowska

b.gurzkowska@ipczd.pl

Zbigniew Kułaga

z.kulaga@ipczd.pl

Aneta Grajda

a.grajda@ipczd.pl

Magdalena Góźdź

m.gozdz@ipczd.pl

Małgorzata Wojtyło

m.wojtylo@czd.pl

1 Public Health Department, The Children's Memorial Health Institute, al. Dzieci Polskich 20, 04-730 Warsaw, Poland

2 Department of Nephrology and Arterial Hypertension, The Children's Memorial Health Institute, al. Dzieci Polskich 20, 04-730 Warsaw, Poland middle-secondary, prevalence of thinness decreased among boys and increased among girls. Thin students were significantly shorter than other students, and thin girls less likely participated in physical education.

Conclusion: Gender and socioeconomic factors are important determinants of thinness among Polish children and adolescents. Public health strategies should address family eating practices to prevent negative effects of weight deficit, especially among girls/children from low GDP regions.

What is Known:

- Socioeconomic factors and gender influence weight status of children and adolescents.

What is New:

- The first time the prevalence and determinants of thinness based on data from a nationally representative, weighted sample of Polish children aged 7-18 years were presented.

- The analysis shows how gender and socioeconomics determinants influence the prevalence of thinness among children and adolescent in post-transformation country and can be used to international comparisons.

Keywords Thinness $\cdot$ Socioeconomic factors $\cdot$ Birth weight . Height
Abbreviations
BMI Body mass index
CI Confidence interval
CMHI Children's Memorial Health Institute
CSO Central Statistical Office
EU European Union
GDP Gross domestic product
IOTF International Obesity Task Force
LBW Low birth weight 
OLAF The "Elaboration of reference blood pressure ranges for children and adolescents in Poland" PL0080 study

OR Odds ratio

PE Physical education

PLN Polish zloty (units of Polish currency)

PSU Primary sampling unit

SE Standard error

SES Socioeconomic status

\section{Introduction}

Nutritional status assessment plays an important role in evaluating the health status of the population. Measurements of weight and height and analysis of body mass index (BMI) are a simple method which is used in the nutritional status assessment of children and adolescents [18]. Both thinness and overweight affects children's development and reaching their optimal potential of good health [22].

Being thin may be due to both genetic and external factors, related to the child's environment. Inadequate intake of energy and nutrients that may be associated with the limited resources of food, stress or an unbalanced diet used in a medical disorder (e.g. allergy) or poor eating habits are the most common causes of low weight to height ratio in adolescents. Insufficient supply of protein, energy or micronutrients may lead to malnutrition, which may also result in reducing the body's resistance to pathogens, delayed physical and intellectual development or cause metabolic disorders. Underweight, although to a lesser extent than obesity, affects the morbidity of children and adolescents [15].

The aim of this study was to investigate the prevalence of thinness among children and adolescents in the context of socioeconomic determinants, gender, body height and birth weight.

\section{Materials and methods}

\section{Study population and sampling}

This study used nationally representative data from the OLAF study ("Elaboration of reference blood pressure ranges for children and adolescents in Poland"-PL0080 (OLAF)). The study protocol was approved by the Bioethics Committee of the Children's Memorial Health Institute (CMHI). The studied population comprised school students, who between school years 2007-2008 and 2009-2010 attended primary, middle and secondary schools. Participants were selected in a two-stage random sampling procedure. The primary sampling unit (PSU) was a school sampled from an all-schools-in-Poland sampling frame provided by the Polish
Ministry of Education. The schools were selected by stratified sampling with probability proportional to the size of the unit. In respect of primary and middle schools, the strata were urban/rural, whereas for secondary schools, the kind of school. In the second stage, the participants were randomly selected based on the number of students in a given school. There were 24,814 students randomly selected and invited to take part in the study, of whom 17,573 children and adolescents (8396 boys) participated in this study (response rate $71 \%$ ).

\section{Data collection}

Informed consent for participation in the study was obtained in writing from the parents (or guardians) of students under the age of 18 years, as well as from participants over the age of 16 years. Body height and body weight were measured according to the procedures delineated in the OLAF study protocol and described previously [13]. Height was measured in duplicate using a stadiometer (SECA 214) in the standing position (without shoes), to the nearest millimetre. Body weight was measured in light underwear twice, using a digital, medical scale (Radwag WPT 100/200), and was recorded to the nearest $0.05 \mathrm{~kg}$. A detailed description of the sampling, as well as description of procedures for anthropometric measurements, is included in earlier publication [13].

BMI was calculated as the ratio of weight in kilograms and the square of height in meters.

The age of the study participant was calculated from the difference between the date of measurement and the date of birth. Thinness was defined according to gender and agespecific BMI cut-off points by Cole TJ et al. [4]; overweight and obesity was defined based on BMI cut-off points according to the International Obesity Task Force (IOTF) [3]. Body weight categories were assigned using LMSgrowth (downloaded from the website http://homepage.mac.com/ tjcole/FileSharing1.html).

Data on health status (including birth weight), as well as the socio-economic and environmental situation of the student, were collected with the use of the questionnaire completed by parents or adult study participants. The following explanatory variables were recorded: maternal education (higher, secondary, primary or vocational); household monthly income per capita in Polish currency (PLN): less than 500 PLN, 5011000 PLN, more than 1000 PLN; the area of the school location (urban big city, urban other, rural); level of schooling (primary, middle, secondary) and participation in physical education (the variable was dichotomised according to the answer to question "Is your child participating in physical education classes?"). Maternal education level and household monthly income per capita were considered as indicators of socioeconomic status (SES).

In order to examine the relationship between the level of the GDP and thinness, the area of the country was divided into 
regions: region 1 in which the GDP per inhabitant was above $150 \%$ of the national average, region 3 in which the GDP per inhabitant was below $80 \%$ of the national average and region 2 in which the GDP per inhabitant was between 150 and $80 \%$ of the national average [8].

Urban and rural area was defined according to the Central Statistical Office of Poland (CSO) classification. In urban areas, cities with over 500,000 residents were selected as "big cities". Only primary and middle schools were included in the analysis of the school location, because almost all secondary schools were located in urban areas.

\section{Statistical analysis}

Statistical analysis was performed using SAS statistical software version 9.4. The survey data were weighted against the CSO 2008 census demographic estimates. The weight construction included gender, age and region, so that the sample reflects structure of Polish population aged 7-18 years. Descriptive statistics were performed with the use of Proc Surveymeans and Proc Surveyfreq providing unweighted sample sizes and weighted means or proportions. Standard errors were adjusted for clustering at the PSU level. Thinness and overweight including obesity proportions and proportions of thinness according to the birth weight category, GDP, and schooling level categories were compared with the use of Rao-Scott Chi-Square test. The associations of thinness and birth weight categories with height expressed as z-scores relative to the Polish 2010 growth references [13] were examined with the use of multiple linear regression. Logistic regression, which incorporates a complex survey sample design, was performed to obtain adjusted odds ratios (ORs) and 95\% confidence intervals (95\% CIs), measuring the association between gender and other exposure variables and the odds of being thin, in univariate models. Finally, a multivariable logistic regression analysis was performed with thinness as the dependent variable. The associations were examined separately for boys and girls. Weighted percentages of nonparticipation in physical education classes and its ORs with 95\% CIs were calculated according to the weight status categories. Values of $p<0.05$ were considered statistically significant. A sequential Bonferroni correction was applied to adjust the significance level of multiple comparisons.

\section{Results}

Among the 17,573 students who participated in the study, 123 were younger than 7 or older than 18 years, thus the data were not included in the analysis. In the case of 16 students, height and/or weight measurements were missing; we also excluded the data of young women who at the time of the study were pregnant (7 women). Finally, the data from 17,427 students
(52.2\% girls) were analysed. For some analyses, the number of participants was smaller due to missing data: 459 for maternal education, 5344 for income per capita, 1835 for birth weight and/or 226 for physical activity. Descriptive statistics of the sample: unweighted sample sizes and weighted means or proportions are given in the Table 1 .

\section{Body weight distribution by BMI category and thinness grade}

Thinness was less frequent than overweight including obesity (11.7 vs $16.5 \% ; p<0.01)$. Analysis by gender revealed that among boys, the prevalence of thinness was significantly lower compared to the prevalence of overweight including obesity $(p<0.01)$; in the group of girls, the prevalence of thinness and overweight including obesity were similar $(p=0.27)$ (Table 1).

Thinness grade 1 accounted for $9.6 \%$, grade 2 for $1.6 \%$ and grade 3 for $0.5 \%$ of all children. Thinness grade distribution has been presented in Table 1 . Female sex significantly increased odds of being thin: $\mathrm{OR}=1.43$ (CI 1.29-1.59) and $\mathrm{OR}=1.32$ (CI 1.18-1.48), OR $=1.92$ (CI 1.46-2.53) and $\mathrm{OR}=1.79(\mathrm{CI} 1.12-2.86)$ for thinness of all grades and grades 1,2 and 3 , respectively $(p<0.01$ for thinness all grades and grades 1 and 2 and $p=0.016$ for grade 3 ).

\section{Thinness, birth weight and body height}

Thinness was more prevalent in children who had low birth weight (LBW; less than $2500 \mathrm{~g}$ ): 16.1 vs $11.6 \%$, LBW vs nonLBW, respectively; $p<0.01$. LBW increased odds of being thin in the case of boys $(p<0.01)$, but not in the case of girls (Table 2). The weighted mean height $\mathrm{z}$-score was significantly lower in the case of thin boys and girls in comparison with not thin peers (non-overlapping confidence intervals of the mean) with the exception of LBW girls (Fig. 1.)

Thinness and LBW were independently, significantly negatively associated with body height in boys and girls (Table 3 ).

\section{Thinness according to maternal education and household monthly income per capita}

The prevalence of thinness was highest among boys and girls of mothers whose educational level was low and in families which declared low income per capita; however, these differences lacked statistical significance: thinness weighted ORs 95\% CI include 1 (Table 2).

\section{Thinness and GDP per inhabitant}

The prevalence of thinness among students increased with a decrease in the GDP per inhabitant in regions ( 8.9 vs. 11.8 vs. 
Table 1 Summary of study sample characteristics

\begin{tabular}{|c|c|c|c|c|c|c|c|}
\hline \multirow[t]{2}{*}{ Variable } & & \multicolumn{3}{|l|}{ Boys } & \multicolumn{3}{|l|}{ Girls } \\
\hline & & $N^{\mathrm{a}}$ & Mean or proportion ${ }^{\mathrm{b}}$ & SE & $N^{\mathrm{a}}$ & Mean or proportion ${ }^{\mathrm{b}}$ & SE \\
\hline & Age (years) & 8327 & 13.0 & 0.18 & 9100 & 13.0 & 0.18 \\
\hline & Height $(\mathrm{cm})$ & 8327 & 157.8 & 0.97 & 9100 & 152.6 & 0.68 \\
\hline & Weight $(\mathrm{kg})$ & 8327 & 50.3 & 0.84 & 9100 & 45.7 & 0.60 \\
\hline & BMI $\left(\mathrm{kg} / \mathrm{m}^{2}\right)$ & 8327 & 19.4 & 0.11 & 9100 & 19.1 & 0.10 \\
\hline & Height z-score & 8327 & 0.0 & 0.01 & 9100 & 0.0 & 0.01 \\
\hline & BMI z-score & 8327 & 0.0 & 0.01 & 9100 & 0.0 & 0.01 \\
\hline & Birth weight (g) & 7387 & 3433.0 & 7.41 & 8206 & 3281.0 & 6.66 \\
\hline \multirow[t]{2}{*}{ Low birth weight $(<2500 \mathrm{~g})$} & Yes & 358 & 4.7 & 0.27 & 554 & 6.7 & 0.27 \\
\hline & No & 7029 & 95.3 & 0.27 & 7652 & 93.3 & 0.27 \\
\hline \multirow[t]{6}{*}{ Body weight category } & Normal weight & 5932 & 71.5 & 0.57 & 6550 & 72.1 & 0.55 \\
\hline & Overweight incl. obesity & 1562 & 18.6 & 0.53 & 1304 & 14.3 & 0.46 \\
\hline & Thinness all grades & 833 & 9.9 & 0.36 & 1246 & 13.6 & 0.42 \\
\hline & Thinness grade 1 & 713 & 8.4 & 0.34 & 996 & 10.8 & 0.37 \\
\hline & Thinness grade 2 & 91 & 1.1 & 0.11 & 193 & 2.1 & 0.17 \\
\hline & Thinness grade 3 & 29 & 0.4 & 0.07 & 57 & 0.6 & 0.09 \\
\hline \multirow[t]{3}{*}{ Maternal education } & University & 1577 & 19.1 & 0.94 & 1611 & 18.1 & 0.92 \\
\hline & Secondary & 3247 & 40.1 & 0.64 & 3431 & 38.4 & 0.72 \\
\hline & Primary or vocational & 3280 & 40.7 & 1.12 & 3822 & 43.6 & 1.17 \\
\hline \multirow[t]{3}{*}{ Type of school } & Primary & 4372 & 50.1 & 2.99 & 4337 & 49.7 & 2.97 \\
\hline & Middle & 2114 & 27.0 & 2.68 & 2258 & 26.6 & 2.65 \\
\hline & Secondary & 1841 & 22.8 & 2.32 & 2505 & 23.7 & 2.36 \\
\hline \multirow[t]{3}{*}{ School location $^{\mathrm{c}}$} & Big city & 591 & 8.9 & 1.94 & 636 & 9.5 & 2.06 \\
\hline & Town or small city & 3309 & 51.4 & 3.29 & 3353 & 50.5 & 3.29 \\
\hline & Rural & 2586 & 39.7 & 3.10 & 2606 & 40.0 & 3.11 \\
\hline \multirow[t]{3}{*}{ Income per capita } & $\leq 500$ PLN & 2819 & 48.4 & 1.14 & 3095 & 49.4 & 1.14 \\
\hline & 501-1000 PLN & 1850 & 31.9 & 0.72 & 1968 & 31.5 & 0.69 \\
\hline & $>1000$ PLN & 1139 & 19.7 & 0.91 & 1212 & 19.1 & 0.87 \\
\hline \multirow[t]{3}{*}{ Gross Domestic Product } & Region 1 & 1124 & 13.0 & 1.03 & 1276 & 13.0 & 0.92 \\
\hline & Region 2 & 5253 & 64.0 & 1.51 & 5642 & 64.0 & 1.45 \\
\hline & Region 3 & 1950 & 23.1 & 1.33 & 2182 & 23.1 & 1.29 \\
\hline \multirow[t]{2}{*}{ Participation in physical education } & Yes & 7935 & 96.8 & 0.23 & 8617 & 95.8 & 0.32 \\
\hline & No & 249 & 3.2 & 0.23 & 400 & 4.2 & 0.32 \\
\hline
\end{tabular}

Thinness grade 1, 2 and 3 corresponds to the BMI 17 to $<18.5,16$ to $<17$ and $<16 \mathrm{~kg} / \mathrm{m}^{2}$ at the age of 18 years, respectively.

$S E$ standard error, PLN Polish zloty

${ }^{\text {a Unweighted }}$

${ }^{\mathrm{b}}$ Weighted

${ }^{\mathrm{c}}$ Only pupils from primary and middle schools

$13.0 \% ; p<0.001)$. Region with the lowest GDP per inhabitant significantly increased weighted ORs of thinness (Table 2).

\section{Thinness according to the level of schooling and location of school}

The percentage of thin students varied according to the level of schooling and therefore depended on the age of the students (primary 7-12 years; middle 13-15 years; secondary 1618 years), whereas the direction of change depended on gender. Among boys, the weighted percentage of thinness was highest in primary schools and decreased at subsequent levels of education, while among girls, the opposite: the highest percentage of thinness was found in secondary schools and the lowest in primary schools; the differences between primary and secondary level of schooling were statistically 
Table 2 Univariate associations of exposure variables with thinness weighted percentages

\begin{tabular}{|c|c|c|c|c|c|}
\hline \multirow[t]{2}{*}{ Exposure variable } & & \multicolumn{2}{|l|}{ Boys } & \multicolumn{2}{|l|}{ Girls } \\
\hline & & Thinness (\%) & OR $(95 \% \mathrm{CI})$ & Thinness $(\%)$ & OR $(95 \% \mathrm{CI})$ \\
\hline \multirow[t]{2}{*}{ Birth weight } & $>=2500 \mathrm{~g}$ & 9.8 & ref. & 13.6 & ref. \\
\hline & $<2500 \mathrm{~g}$ & 17.6 & $1.96(1.44-2.66)$ & 15.7 & $1.14(0.88-1.47)$ \\
\hline \multirow[t]{3}{*}{ Maternal education } & University & 9.4 & ref. & 12.3 & ref. \\
\hline & Secondary & 9.4 & $1.03(0.82-1.29)$ & 13.5 & $1.09(0.90-1.32)$ \\
\hline & Primary or vocational & 10.7 & $1.15(0.91-1.44)$ & 14.3 & $1.14(0.93-1.38)$ \\
\hline \multirow[t]{3}{*}{ Income per capita } & $\leq 500$ PLN & 10.9 & ref. & 14.3 & ref. \\
\hline & 501-1000 PLN & 9.6 & $0.91(0.74-1.12)$ & 13.8 & $0.98(0.82-1.16)$ \\
\hline & $>1000$ PLN & 9.2 & $0.85(0.65-1.10)$ & 12.7 & $0.87(0.71-1.08)$ \\
\hline \multirow[t]{3}{*}{ Schooling level } & Primary & 11.0 & ref. & 12.8 & ref. \\
\hline & Middle & 10.3 & $0.93(0.78-1.11)$ & 13.7 & $1.09(0.91-1.30)$ \\
\hline & Secondary & 7.0 & $0.61(0.49-0.77)$ & 15.0 & $1.20(1.03-1.41)$ \\
\hline \multirow[t]{3}{*}{ School location ${ }^{\mathrm{a}}$} & Big city & 10.9 & ref. & 10.3 & ref. \\
\hline & Town or small city & 10.9 & $1.01(0.74-1.37)$ & 13.5 & $1.36(1.02-1.81)$ \\
\hline & Rural & 10.5 & $0.96(0.70-1.32)$ & 13.3 & $1.34(1.00-1.79)$ \\
\hline \multirow[t]{3}{*}{ Gross domestic product } & Region 1 & 7.7 & ref. & 10.2 & ref. \\
\hline & Region 2 & 9.9 & $1.33(0.98-1.79)$ & 13.7 & $1.39(1.13-1.71)$ \\
\hline & Region 3 & 10.9 & $1.47(1.06-2.05)$ & 15.2 & $1.57(1.23-1.99)$ \\
\hline
\end{tabular}

CI confidence interval, $O R$ odds ratio, $P L N$ Polish zloty

${ }^{a}$ Only pupils from primary and middle schools

significant (Fig. 2). In comparison to primary level, secondary level of schooling increased OR of thinness in the case of girls, but in the case of boys, it decreased (Table 2).

The highest percentage of thin girls was recorded in schools located in urban areas outside the cities inhabited by more than 500,000 residents. In girls, thinness OR was significantly higher in comparison to big city vs town or small city and vs rural. There was no significant difference in the case of boys (Table 2).

\section{Multivariable models for thinness}

In the multiple logistic models, explanatory variables, which showed statistical significance in univariate analysis with
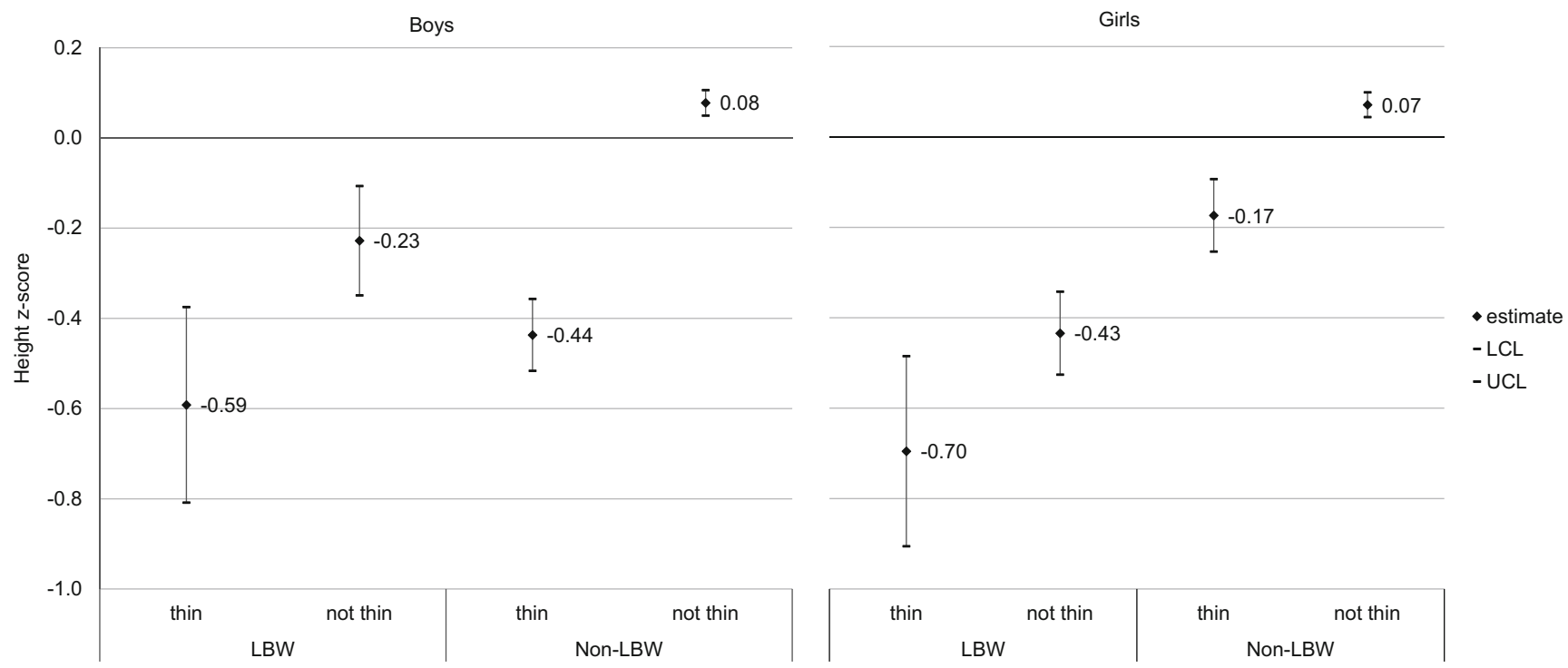

Fig. 1 The weighted means of height $z$-score in thin and not thin girls and boys according to the birth weight category. $L C L, U C L$ lower and upper confidence limit of $95 \%$ CI, $L B W$ low birth weight $(<2500 \mathrm{~g})$. Non-LBW: birth weight $\geq 2500 \mathrm{~g}$ 
Table 3 Results of multiple regression models of thinness and low birth weight as explanatory variables for body height (expressed as a zscore)

\begin{tabular}{|c|c|c|c|c|c|c|}
\hline & \multicolumn{3}{|l|}{ Boys } & \multicolumn{3}{|l|}{ Girls } \\
\hline & Estimate $^{\mathrm{a}}$ & SE & $p$ & Estimate $^{\mathrm{a}}$ & $\mathrm{SE}$ & $p$ \\
\hline Intercept & 0.08 & 0.01 & $<0.01$ & 0.07 & 0.01 & $<0.01$ \\
\hline Thinness & -0.50 & 0.04 & $<0.01$ & -0.25 & 0.04 & $<0.01$ \\
\hline Low birth weight & -0.28 & 0.06 & $<0.01$ & -0.51 & 0.04 & $<0.01$ \\
\hline
\end{tabular}

${ }^{\mathrm{a}}$ Weighted

thinness, were included with the exception of "School location", which was not included due to the fact that school location on secondary level did not allow differentiating records to urban-rural levels. The LBW and lowest GDP region were found to be independent risk factors for thinness in the case of boys, whereas secondary level of schooling decreased odds of thinness. In the case of girls, secondary level of schooling and regions with lower than highest GDP were increasing odds of thinness (Table 4).

\section{Participation in physical education}

In both boys and girls, weighted frequency of nonparticipation in physical education classes was the lowest in the group of normal weight. Among girls, thinness (but not overweight), compared to normal weight, increased weighted odds of non-participation in physical education classes. There was an opposite pattern in the case of boys: weighted odds of non-participation in physical education were increased with overweight but not thinness (Table 5).

\section{Discussion}

Due to the growing epidemic of overweight and obesity, the focus of researchers remained mainly to excessive body weight [2, 7, 20, 21, 24]. Our analysis showed that although weight deficit among students was less frequent than overweight and obesity (jointly), in the group of girls, the proportion of thinness was similar to the percentage of overweight and obesity. Weight deficiency more often affected girls than boys, while overweight and obesity was more common among boys [9].

Our data show that among socioeconomic determinants, only GDP per inhabitant in the region was found to be an independent risk factor for thinness.

It should be noted that in the year preceding the survey in five Polish districts, called in paper region 3, GDP per inhabitant was below $40 \%$ for the European Union and only in Masovian district (region 1) exceeded $75 \%$ for the EU [8]. In Poland according to the CSO, the average monthly household per capita income in 2008 was 1046 PLN, i.e. about 250 Euro, and a household per capita income below 500 PLN for many years entitles the family to apply for child benefits. Generally low level of household income per capita in Poland may be related to low differentiation of thinness in relation to the economic status. In addition, lack of statistically significant association with income may be linked to relatively

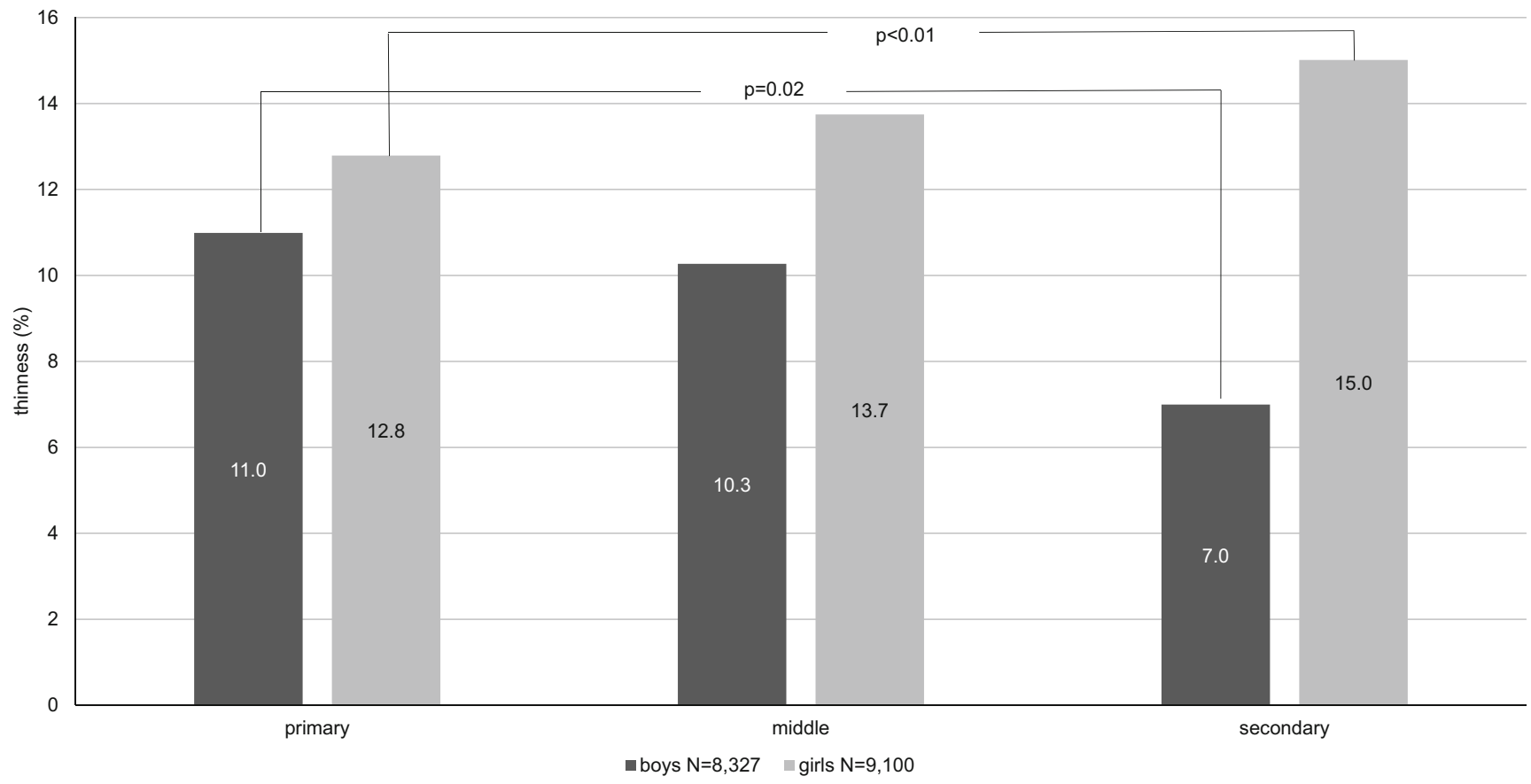

Fig. 2 The weighted prevalence of thinness by the level of schooling 
Table 4 Results of multivariable logistic regression models with thinness as dependent variable

\begin{tabular}{lll}
\hline & $\begin{array}{l}\text { Boys } \\
\text { Thinness OR }\end{array}$ & $\begin{array}{l}\text { Girls } \\
\text { Thinness OR } \text { OR }^{\mathrm{a}}(95 \% \mathrm{CI})\end{array}$ \\
\hline Low birth weight & $1.89(1.38-2.57)$ & $1.13(0.87-1.46)$ \\
Schooling level middle vs primary & $0.97(0.81-1.16)$ & $1.16(0.97-1.38)$ \\
Schooling level secondary vs primary & $0.63(0.50-0.81)$ & $1.19(1.01-1.40)$ \\
GDP region 2 vs 1 & $1.27(0.95-1.71)$ & $1.40(1.12-1.74)$ \\
GDP region 3 vs 1 & $1.39(1.00-1.92)$ & $1.56(1.21-2.01)$ \\
\hline
\end{tabular}

${ }^{\mathrm{a}}$ Weighted high frequency of missing data on income provided by the study questionnaire.

Results of our analysis with regard to low impact of material factors on thinness prevalence among children and adolescents is in line with observations of other researchers [6].When considering the shaping of body weight, gender appears to be an important factor, not only because of the scale of the phenomenon but also in the context of socio-economic, environmental and psychological determinants. Although the percentage of thinness was higher in the LBW children, only in boys, the difference was statistically significant. Similarly, differences in thinness prevalence according to age groups, from primary to secondary schooling level, show opposite trend: decrease in boys and increase in girls. It may indicate a gendered mechanism of formation and maintenance of a body weight deficiency [6].

Confirmation of the different approaches of boys and girls to their body weight can be found in the results of the study of youth aged 16-18 years, carried out in 2005 in Warsaw [17]. In this study, girls significantly more often declared that they were currently (at the time of the study) taking action to reduce body weight $(26 \%)$ than were boys $(9 \%)(p<0.001)$; girls prevailed also among those who in the past 12 months preceding the study, in order to reduce weight, applied methods risky to health, e.g. a starvation diet, induced vomiting, use of diet pills or laxatives ( $15 \%$ of boys vs $25 \%$ girls, $p<0.001$ ). Taking action to reduce weight was related to the subjective assessment of body weight. In all categories of body weight, statistically significant differences were found between boys and girls in the self-assessment of body weight. Boys more often assessed themselves as too thin and girls as too fat. Almost $40 \%$ of boys with excessive body weight evaluated their body mass as appropriate, and over $50 \%$ of girls with an average body weight saw themselves as too fat; $17 \%$ of underweight girls also assessed themselves as too fat [17].

It should be noted that the study of Whitaker et al. [23] indicates that paediatric thinness is associated with the familial tendency to have low body weight, and thus intergenerational thinness transmission, which supports the view that many cases of underweight represents a low level of distribution of healthy body weight having genetic origin.

In European countries, as well as in Australia, the prevalence of underweight among children and adolescents is about 4-8\% $[5,14,16]$. In the Polish study, in the analysis of changes in the prevalence of underweight among children and adolescents aged 7-18 years in Łódź within the 26 years of transformation (both economic and political), Żądzińskia et al. [25] observed an increase in body weight deficiency in the years $1977 / 1978$ and 2002/2004, in the group of boys from 7.2 to $12.1 \%$ and in the group of girls from 11.0 to $20.2 \%$. In comparison to other European countries, it is a disturbing trend.

Researchers from the Czech Republic noted in 2001 as compared to 1991 a decrease in the percentage of students with a very low BMI among younger school-age children

Table 5 Weighted percentages of students not participating in physical education classes according to the weight status groups and logistic regression analyses of the association of weight status with non-participation in physical education classes

\begin{tabular}{|c|c|c|c|c|}
\hline \multirow[t]{2}{*}{ Weight status } & \multicolumn{2}{|l|}{ Boys } & \multicolumn{2}{|l|}{ Girls } \\
\hline & $\begin{array}{l}\text { non-participation in } \\
\text { PE classes }(\%)^{\mathrm{a}}\end{array}$ & $\mathrm{OR}^{\mathrm{a}}(95 \% \mathrm{CI})$ & $\begin{array}{l}\text { Non-participation in } \\
\text { PE classes }(\%)^{\mathrm{a}}\end{array}$ & $\mathrm{OR}^{\mathrm{a}}(95 \% \mathrm{CI})$ \\
\hline Thinness & 3.1 & $1.05(0.69-1.61)$ & 6.0 & $1.61(1.22-2.12)$ \\
\hline Normal weight & 2.9 & ref. & 3.8 & ref. \\
\hline Overweight $^{\mathrm{b}}$ & 4.1 & $1.4(1.01-1.94)$ & 4.1 & $1.06(0.77-1.47)$ \\
\hline
\end{tabular}

$P E$ physical education

${ }^{\text {a }}$ Weighted

${ }^{\mathrm{b}}$ Including obesity 
and a sharp increase in adolescence. In assessing this phenomenon as negatively as the increase in the percentage of obese people in the population, they discerned its causes in poor nutrition due to diets aiming to achieve a very slim figure, which is currently in fashion, and increasing anorexia, especially among teenage girls [12]. In Polish studies of secondary and high school students, the percentage of respondents who declared anorexia was $6.9 \%$, including $4.3 \%$ of respondents with normal body weight and $1.6 \%$ with underweight. In this study, the percentage of underweight adolescents and young adults was $12.7 \%$ for males and $21.5 \%$ for females. The highest frequency of underweight was reported in rural areas, and the lowest in cities with populations of more than 100,000 residents [10].

In the current analysis, a significant difference in the prevalence of thinness in the group of school-aged girls in urban areas was reported; the lowest percentage of thinness was observed among girls in cities with populations of more than 500,000 residents. Among girls, the prevalence of thinness in the other urban areas and in rural areas was comparable. The lowest prevalence of thinness among students in big cities may be associated with the higher level of women's education and higher income of residents of big cities (data not shown); in Poland, there are no big cities (with populations of more than 500,000 residents) in the region with low GDP per inhabitant (below $80 \%$ of the national average).

Low body mass may have a negative impact on the physical development of school-age children and adolescents. In the group of thin girls, the relatively high percentage of students who did not participate in physical education drew attention; it is greater than in the group with normal body weight and even greater than in the group with excess body weight, which can affect the physical ability and general body efficiency of thin girls. Researchers who studied differences in health-related fitness among Spanish adolescents classed as underweight, normal weight, overweight or obese according to BMI concluded that not only overweight and obesity but also underweight seem to be determinants of health-related fitness in adolescents [1].

The average body height of thin girls and boys, independent of birth weight, was significantly lower than of students who were not thin. It may indicate that underweight children do not realize their full potential in terms of body height. However, due to the fact that the study did not examine the relationship between BMI of children and parents, the effect of the primary limitations of biological and/or cultural potential for the occurrence of underweight cannot be excluded.

As reported by other researchers, in the case of girls, underweight is of particular importance in the context of future motherhood [11, 19]. The number of infants born before 32 weeks was significantly higher in the group of underweight mothers, compared to the group with normal weight before pregnancy. Underweight mothers were at increased risk for low birth weight and very low birth weight of newborns. In addition, deficient female body weight before pregnancy may pose a risk to the newborn of developing respiratory distress syndrome and anaemia $[11,19]$. In this context, the increase in the proportion of girls with a deficiency of body weight is a phenomenon of a negative nature, the consequences of which can be transferred to the next generation.

\section{Strength and limitations}

The main strength of this study is that it is a large, nationally representative sample of school-aged children and adolescents which provided data on socioeconomic status and measured height and weight.

Statistical analysis accounted for complex sampling design of the survey; all analyses applied weights and cluster structure of the two-stage sample.

The main limitation of the study is response rate of $71 \%$ and the relatively high frequency of missing income data.

\section{Conclusions}

For the first time, the prevalence and determinants of thinness based on data from a nationally representative, weighted sample of Polish children aged 7-18 years were presented. Gender and the socioeconomic factors, GDP region, were important determinants of thinness among Polish children and adolescents. The analysis shows how socioeconomics determinants and gender influence the prevalence of thinness among children and adolescents in post-transformation country and can be used for international comparisons. Public health strategies should address family eating practices to prevent negative effects of weight deficit, especially among girls/children from low GDP regions.

Acknowledgments The OLAF study was supported by a grant from Iceland, Liechtenstein and Norway through the EEA Financial Mechanism and the Norwegian Financial Mechanism and the Ministry of Science and Higher Education of Poland (grant number PL0080). Head of the research project: Mieczysław Litwin.

The OLAF Study Group: Medical University of Białystok: Agnieszka Rybi-Szumińska, Michał Szumiński, Katarzyna Taranta-Janusz, Edyta Tenderenda, Anna Wasilewska; Regional Children's Hospital in Bydgoszcz: Beata Jasińska; Medical University of Gdańsk: Piotr Czarniak, Dominik Świętoń, Przemysław Szcześniak; Jagiellonian University, Medical College in Kraków: Monika Miklaszewska, Anna Moczulska, Katarzyna Wilkosz, Katarzyna Zachwieja, Iwona Ogarek; Medical University of Lublin: Marek Majewski, Aleksandra Sobieszczańska-Droździel, Izabela Szlązak, Paweł Szlązak, Małgorzata Zajączkowska; Polish Mother's Memorial Hospital Research Institute in Łódź: Monika Pawlak-Bratkowska, Anna Półtorak-Krawczyk,Marcin Tkaczyk; District Hospital in Kędzierzyn-Koźle: Danuta Gmyrek; Poznan University of Medical Sciences: Tomasz Krynicki, Jolanta Sołtysiak; Regional Children's Hospital in Toruń: Roman Stankiewicz, 
Sława Zbucka; The Children's Memorial Health Institute in Warszawa: Ewelina Napieralska-Stencel, Anna Świąder-Leśniak, Agnieszka Różdżyńska-Świątkowska, Robert Pietruczuk, Jan Szpor; Wroclaw Medical University: Jacek Kleszczyński, Magdalena Naleśniak, Anna Wawro, Irena Wikiera-Magott; Medical University of Silesia: Piotr Adamczyk, Tatiana Augustyn-Iwachów, Beata Banaszak, Omar Bjanid, Katarzyna Broll-Waśka, Aurelia Morawiec-Knysak.

Authors' contributions Beata Gurzkowska conceived the study; collected, assembled and processed data; performed statistical analyses; performed literature search and wrote the manuscript. Zbigniew Kułaga conceived the study, conducted field examinations, performed quality data control and statistical analyses and critically reviewed the manuscript. Aneta Grajda conceived the study, conducted field examinations, performed statistical analyses and drafted the manuscript. Magdalena Góźdź collected, assembled and processed data; quality data control and critically reviewed the manuscript. Małgorzata Wojtyło collected, assembled and processed data and critically reviewed the manuscript. Mieczysław Litwin, Principal Investigator of the OLAF project, conceived the study and supervised the final version of the manuscript.

\section{Compliance with ethical standards}

Ethical approval All procedures performed in studies involving human participants were in accordance with the ethical standards of the institutional and/or national research committee and with the 1964 Helsinki Declaration and its later amendments or comparable ethical standards. The study protocol was approved by the Bioethics Committee of the CMHI, ref. no: 166/KBE/2005.

Informed consent Informed consent was obtained in writing from the parents (or guardians) of all individual participants under the age of 18 years, as well as from all individual participants over the age of 16 years, included in the study.

Conflict of interest The authors declare that they have no conflict of interest

Open Access This article is distributed under the terms of the Creative Commons Attribution 4.0 International License (http:// creativecommons.org/licenses/by/4.0/), which permits unrestricted use, distribution, and reproduction in any medium, provided you give appropriate credit to the original author(s) and the source, provide a link to the Creative Commons license, and indicate if changes were made.

\section{References}

1. Artero EG, España-Romero V, Ortega FB, Jiménez-Pavón D, Ruiz JR, Vicente-Rodríguez G, Bueno M, Marcos A, Gómez-Martínez S, Urzanqui A, González-Gross M, Moreno LA, Gutiérrez A, Castillo MJ (2010) Health-related fitness in adolescents: underweight, and not only overweight, as an influencing factor. The AVENA study. Scand J Med Sci Sports 20(3):418-427

2. Bac A, Woźniacka R, Matusik S, Golec J, Golec E (2012) Prevalence of overweight and obesity in children aged 6-13 years - alarming increase in obesity in Cracow, Poland. Eur J Pediatr 171(2):245-251

3. Cole TJ, Bellizzi MC, Flegal KM, Dietz WH (2000) Establishing a standard definition for child overweight and obesity worldwide: international survey. Brit Med J 320(7244):1240-1243
4. Cole TJ, Flegal KM, Nicholls D, Jackson AA (2007) Body mass index cut offs to define thinness in children and adolescents: international survey. Brit Med J 335(7612):194

5. Ferrar K, Olds T (2010) Thin adolescents: who are they? What do they do? Socio-demographic and use-of-time characteristics. Prev Med 51:253-258

6. Godley J, McLaren L (2010) Socioeconomic status and body mass index in Canada: exploring measures and mechanisms. Can Rev Sociol 47:381-403

7. Goldfield GS, Murray M, Maras D, Wilson AL, Phillips P, Kenny GP, Hadjiyannakis S, Alberga A, Cameron JD, Tulluch H, Sigal RJ (2016) Screen time is associated with depressive symptomatology among obese adolescents: a HEARTY study. Eur J Pediatr 175: 909-919

8. Gross Domestic Product. Regional accounts in 2007. Central Statistical Office, Statistical Office in Katowice. Katowice 2009. http://stat.gov.pl/cps/rde/xbcr/gus/rn_pkb_rachunki_regionalne w 2007.pdf. Accessed 30 May 2016

9. Gurzkowska B, Kułaga Z, Litwin M, Grajda A, Świąder A, Kułaga K, Góźdź M, Wojtyło M (2014) The relationship between selected socioeconomic factors and basic anthropometric parameters of school-aged children and adolescents in Poland. Eur J Pediatr 173:45-52

10. Kapka-Skrzypczak L, Bergier B, Diatczyk J, Niedźwiecka J, Biliński P, Wojtyła A (2012) Dietary habits and body image perception among polish adolescents and young adults - a population based study. Ann Agric Environ Med 19(2):299-308

11. Kaźmierczak J, Reszczyńska M, Szymański W, Daniłko M (2009) Znaczenie masy ciała matek dla przebiegu porodu oraz adaptacji okołoporodowej noworodków. Perinatol Neonatol Ginekol 4(2): 266-273

12. Kobzová J, Vignerová J, Bláha P, Krejčovsky L, Riedlová J (2004) The $6^{\text {th }}$ nationwide anthropological survey of children and adolescents in the Czech Republic in 2001. Cent Eur J Public Health 12(3):126-130

13. Kułaga Z, Litwin M, Tkaczyk M, Palczewska I, Zajączkowska M, Zwolińska D, Krynicki T, Wasilewska A, Moczulska A, Morawiec-Knysak A, Barwicka K, Grajda A, Gurzkowska B, Napieralska E, Pan H (2011) Polish 2010 growth references for school-aged children and adolescents. Eur J Pediatr 170(5):599 609

14. Lazzeri G, Ross S, Pammolli A, Pilato V, Pozzi T, Giacchi MV (2008) Underweight and overweight among children and adolescents in Tuscany (Italy). Prevalence and short-term trends J Prev Med Hyg 49:13-21

15. Lusky A, Barell V, Lubin F, Kaplan G, Layani V, Shohat Z, Lev B, Wiener M (1996) Relationship between morbidity and extreme values of body mass index in adolescents. Int J Epidemiol 25(4): 829-834

16. Marques-Vidal P, Ferreira R, Oliviera JM, Paccaud F (2008) Is thinness more prevalent than obesity in Portuguese adolescents? Clin Nutr 27:531-536

17. Oblacińska A, Tabak I, Jodkowska M (2007) Eating, dieting and other weight control behaviors of Polish adolescents 16-18- years in the context of body image and body weight perception. Prob Hig Epidemiol 88:162-170

18. Pietrobelli A, Faith MS, Allison DB, Gallagher D, Chiumello G, Heymsfield S (1998) Body mass index as a measure of adiposity among children and adolescents: a validation study. J Pediatr 132: 204-210

19. Salihu HM, Lynch O, Alio AP, Mbah AK, Kornosky JL, Marty PJ (2009) Extreme maternal underweight and feto-infant morbidity outcomes: a population-based study. J Maternal-Fetal Neo M 22(5):428-434

20. Sanders RH, Han A, Baker JS, Cobley S (2015) Childhood obesity and its physical and psychological co-morbidities: a systematic 
review of Australian children and adolescents. Eur J Pediatr 174: 715-746

21. Sousa P, Fonseca H, Gaspar P, Gaspar F (2015) Controlled trial of an Internet-based intervention for overweight teens: effectiveness analysis. Eur J Pediatr 174:1143-1157

22. Suliga E (2006) Anthropometrical methods of assessing nutritional status of children and adolescents. Pediatr Pol 81: 739-746

23. Whitaker KL, Jarvis MJ, Wardle J (2011) The intergenerational transmission of thinness. Arch Pediat Adol Med 165:900-905
24. Wijnhoven T, van Raaij J, Spinelli A et al (2014) WHO European childhood obesity surveillance initiative: body mass index and level of overweight among 6-9-year-old children from school year 2007/2008 to school year 2009/2010. BMC Public Health 14:806

25. Żądzińska E, Rosset I, Kozieł S, Nawarycz T, BorowskaStrugińska B, Lorkiewicz W, Ostrowska-Nawarycz L, Sitek A (2012) Frequency of under- and overweight among children and adolescents during the economic transition in Poland. Homo 63:216-232 